\title{
El USO ARISTOTÉLICO de VARIABLES EN LóGICA Y SUS SUPUESTOS ONTOLÓGICOS
}

Lucas Díaz López

(Doctorando en la Universidad Complutense de Madrid)

\section{0. - Introducción: la actitud lógica}

La "actitud lógica" suele revolverse contra su presunto creador, Aristóteles, detectando en el conjunto de obras conocido como Organon intromisiones y/o prejuicios de índole ontológico-sustantiva, por contraste con la indiferencia formal que esa actitud exige. El propio título compilatorio que se dio a esos escritos es una muestra ya del carácter propedéutico y metodológico que se les presupone ${ }^{1}$. Instrumento, herramienta, lo allí tratado debe servir como el armazón o esqueleto de los distintos saberes materiales, su envoltorio racional, de suerte que, en contrapartida a tal universalidad, ha de corresponderle una vaciedad sustantiva que permita esa pretendida indiferencia. Desde una lectura semejante, cuyo rendimiento histórico resulta, por lo demás, innegable, son enteramente comprensibles las estrategias formalizadoras y, por decirlo así, "purificadoras" con las que se abordan esas obras, ya que, con ello, se pretende estar en consonancia con el "espíritu" de las mismas. Aristóteles sería así el fundador de una disciplina formal, si bien, dada la comprensible ingenuidad de todo comienzo, no pudo llegar a consumar la plena abstracción material ${ }^{2}$. Como epígonos suyos, tarea de los lógicos es depurar los restos

\footnotetext{
${ }^{1}$ Por ejemplo, L. VEGA GONZÁLEZ («La historia de la lógica y el 'caso Aristóteles'», Llull, vol. 5, 1983, pp. 175-207) llega a hablar de la "cabal conciencia" de Aristóteles "de fundar lo que bien podríamos llamar metodología (o teoría) de la argumentación" (p. 176).

${ }^{2}$ Algunos, incluso, achacan a este "pecado original" del fundador los problemas de la posteridad: "Podría resumir lo que voy a decir en una sola sentencia: Aristóteles, como Adán, comenzó bien, pero pronto se extravió por un camino erróneo, con consecuencias desastrosas para su posteridad" (P. T. GEACH, Logic Matters, University of California Press, 1980, p. 44).
}

Philosophica, 38, Lisboa, 2011, pp. 33-57 
omitidos y avanzar por el camino desbrozado por él, desarrollando así plenamente la potencialidad de lo descubierto.

Como contrapunto a un acercamiento de este tipo, el presente artículo tratará de analizar pormenorizadamente un procedimiento concreto de la exposición de las figuras silogísticas: el uso de variables. Este análisis permitirá examinar el rendimiento hermenéutico de estas interpretaciones tradicionales, deslindando posibles puntos de discrepancia que permitan plantear una lectura que encuentre más apego en el texto aristotélico y que dé cuenta, a su vez, de esas divergencias.

\section{1. - La "cualidad" de las variables aristotélicas}

\section{1. - La "incomprensible" limitación de las variables}

La interpretación clásica del uso aristotélico de variables en la exposición de las figuras de la silogística puede ser sintetizada con el siguiente pasaje del manual de historia de la lógica de los Kneale:

"Aristóteles se sirve [en los Analíticos Primeros] de letras como términos-variables, esto es, como signos que indican espacios a rellenar mediante cualesquiera términos generales que elijamos, bajo la sola condición de que los espacios indicados por la misma letra sean rellenados por el mismo término en todos y cada uno de los enunciados que entran en juego en una argumentación dada". ${ }^{3}$

Desde una perspectiva tradicional, por lo tanto, se nos indica ya de entrada que las variables aristotélicas no están constituidas por una absoluta indiferencia respecto al contenido, que no designan cualquier cosa, sino que representan "términos generales". Evidentemente, se puede hacer depender esta limitación de una decisión inicial de exclusión de los "términos singulares", pero con ello sólo se difiere el problema, reenviándolo al de las razones de tal decisión. Quien argumenta, con Lukasiewicz, que "la silogística tal como la concibió Aristóteles requiere que los términos sean homogéneos con respecto a su posible posición como sujetos y predicados" 4 y pretende que esta sea "la verdadera razón por la que los términos singulares fueron omitidos por Aristóteles" ${ }^{5}$ no hace más que enmascarar lo que se piensa que es una decisión arbitraria ("tal como la concibió Aristóteles") bajo un razonamiento aparente. Aparente,

${ }^{3}$ W. KNEALE / M. KNEALE, El desarrollo de la lógica, Madrid, Tecnos, 1980; p. 58.

${ }^{4}$ J. LUKASIEWICZ, La silogística de Aristóteles desde el punto de vista de la lógica formal moderna, Madrid, Tecnos, 1977; pp. 17-18.

${ }^{5}$ Ibid. 
porque el argumento es circular, ya que trata de fundamentar la decisión inicial (la omisión de "términos singulares" y, por tanto, el uso exclusivo de "términos generales") con la consecuencia de esa decisión (la posibilidad de la alternancia funcional). La polivalencia funcional de los términos silogísticos está implicada en la exclusión de los términos singulares, de modo que no la explica sino que, antes bien, la presupone.

Es la decisión de excluir a los "términos singulares" y centrarse en los "términos generales" lo que condiciona la especificidad de las figuras silogísticas, de modo que lo único que el "razonamiento" citado indica es un inconfeso desconocimiento acerca de las razones de tal decisión o, lo que es lo mismo, una suposición de arbitrariedad ${ }^{6}$. Y, desde luego, bajo el prisma de una perspectiva como la de Lukasiewicz ("desde el punto de

${ }^{6}$ De modo semejante se expresa Bochenski: "Se puede preguntar aquí uno por qué razón el fundador de la Lógica, cuya evolución filosófica llegó, con toda seguridad, del platonismo al reconocimiento de la importancia del individuo, ha desatendido completamente en su obra más madura (al contrario del Hermeneia) los términos singulares. La razón de esto radica verosímilmente en que supone que tales términos no son apropiados para predicados, y la técnica silogística exige que todo término extremo aparezca, al menos una vez, como predicado" (I. M. BOCHENSKI, Historia de la Lógica formal, Gredos, Madrid, 1966, p. 83). A lo cual cabe replicar en los mismos términos: no es la índole particular de la "técnica silogística" la que excluye los "términos singulares", sino esta exclusión la que cualifica de ese modo a aquella. Así también, L. VEGA GONZÁLEZ (op. cit., p. 188) aduce la intercambiabilidad (o el interés aristotélico en ella) como uno de los factores de exclusión de los términos singulares (y, añade, de los términos relativos a géneros supremos): "Ahora bien, las ideas de Aristóteles sobre los objetos propios de la investigación científica y su interés en el intercambio de los papeles de sujeto y predicado entre los dos términos de la proposición, le inclinan a prescindir de los términos singulares -pues, normalmente, sólo podrían ejercer de sujetos-, así como de términos relativos a géneros supremos o clases últimas -pues, normalmente, sólo podrían ejercer de predicados-. En suma, Aristóteles se ve llevado a operar con términos generales de alcance medio, entre el extremo inferior del nombre propio y el extremo superior del universal omnipredicable" (más adelante, p. 192, aclara: "es obvio que el interés aristotélico por los términos generales del lenguaje de la silogística obedece a la atención que le merece la ciencia demostrativa", aclaración con la que, como se verá, estamos en parte de acuerdo). D. ROSS, por su parte, en su comentario a Analíticos Primeros, I, 1, 24a17, se limita a reducir a una cuestión de hecho esta exclusión, basada en la mera recurrencia de las cuestiones acerca de "términos universales": "De hecho, los Analíticos Primeros ignoran totalmente juicios acerca de individuos, y el ejemplo de un silogismo que más tarde fue considerado típico -el hombre es mortal, Sócrates es un hombre, luego Sócrates es mortal- es bien diferente de los usados en los Analíticos Primeros, que son todos acerca de universales, siendo una especie el término menor. Las razones aristotélicas de confinarse a argumentos acerca de universales probablemente se encuentran en el hecho, mencionado en 43a42-3, de que 'las discusiones y las investigaciones son, las más de las veces, acerca de especies'.” (p. 289) 
vista de la lógica formal") ello es perfectamente asumible. En efecto, advertir esta autolimitación arbitraria de la silogística aristotélica es la otra cara de superarla, concibiéndola como un caso particular de una disciplina más genérica. La conciencia de esta limitación permite comprender la silogística como "una teoría de las relaciones A, E, I y O en el campo de los términos universales". 7

Entender esta "especialización" de la silogística conlleva, de suyo, la posibilidad de cancelación de la decisión (al fin y al cabo concebida como arbitraria) de limitar el uso de variables a los "términos generales" (o "universales"), lo cual permite a su vez desplegar una noción completa y coherente de la lógica desde un punto de vista exclusivamente formal. En todo este proceso, sin embargo, no hay, como hemos visto, ningún intento de comprender las razones aristotélicas de esa "autolimitación".

\section{2. - Reformulación del problema: la cosa y su determinación}

Enfrentémonos, entonces, con este primer problema, y tratemos de ver, a partir de indicaciones exclusivamente aristotélicas, qué motivos puede haber para cualificar de ese modo a las variables silogísticas. El siguiente pasaje nos dará una idea de la diferencia del planteamiento aristotélico en este punto:

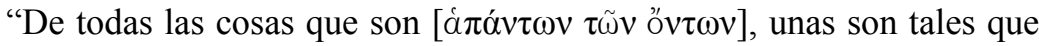
no se predican con verdad de ninguna otra (por ejemplo, Cleón y Calias y lo singular y lo percibido), pero sí otras de ellas (y es que, en efecto, cada una de estas es hombre y animal); otras se predican de otras pero de ellas no se predican cosas anteriores; y otras [se predican] ellas de otras y otras distintas de ellas, como es el caso de hombre de Calias y animal de hombre". ${ }^{8}$

Esta tipología, como puede apreciarse, no se limita al plano lógico-lingüístico de los "términos". Donde la división hasta ahora manejada decía "términos" Aristóteles habla de őv $\tau \alpha$, de cosas que son, de entes, y

\footnotetext{
${ }^{7}$ J. LUKASIEWICZ, op. cit., p. 23. Cfr. también I. M. BOCHENSKI, op. cit., p. 83: "En la silogística tenemos un sistema formal de lógica de los términos variables restringida a términos universales, y que consta de sentencias y no de reglas". L. VEGA GONZÁLEZ (op. cit., p. 191) acierta a explicar esta subordinación como un "espejismo" propio de la "depuración moderna": "el de ver en Aristóteles un lógico axiomático, y en su silogística un subsistema sui generis de la lógica general establecida sobre la base de una matriz postfregeana, hoy asumida como núcleo elemental de la práctica de la disciplina".

${ }^{8}$ Analíticos Primeros, I, 27, 43a25-32.
} 
precisamente de entes de los que se predican o son predicados de otros ${ }^{9}$. Las consideraciones aristotélicas lejos de confinarse en el territorio de lo meramente lingüístico o lógico, corresponden más bien a un ámbito en donde se reúnen inseparablemente ôv y $\lambda o ́$ ós. La clasificación es un análisis de las maneras como se predican los entes, lo cual implica un planteamiento en donde dos esferas para nosotros separadas de un modo evidente se encuentran sin embargo confundidas y entremezcladas. Una expresión como la de que "un ente se predique de otro" no tiene sentido desde un punto de vista que se halla instalado de inicio en la separación (y necesidad de unión, "correspondencia") de lo meramente lingüístico y lo real. Las declaraciones de Lukasiewicz con respecto a este pasaje son un síntoma claro de ello:

"No es correcto decir que una cosa puede ser predicado de otra cosa. Las cosas no pueden ser predicadas, porque un predicado es una parte de una proposición y una proposición es una serie de expresiones habladas o escritas que tiene un cierto significado. El término 'Calias' puede ser predicado de otro término, pero jamás la cosa Calias. La clasificación dada no es una clasificación de cosas, sino una división de términos". 10

Al enfrentarse a este pasaje, una "actitud lógica" se ve obligada a "purificarlo": Aristóteles no puede hablar de cosas que se predican, luego se expresa mal y la clasificación es, en realidad, de términos. Sin embargo, es la mera predisposición a ver en estos tratados nada más que aquello que se circunscribe al ámbito lógico-lingüístico lo que incita a entender őv $\alpha$ como un defecto de expresión fácilmente ignorable. Frente a este exceso de interpretación, trataremos en este punto de permanecer fieles al texto aristotélico, teniendo en cuenta que no es este lugar para intentar hacernos cargo de esta inseparabilidad lógico-ontológica que, por lo demás, puede rastrearse también en otros lugares del pensamiento griego. Manejándola, más bien, a modo de hipótesis de trabajo, intentaremos extraer sus consecuencias para los planteamientos aristotélicos.

Lo siguiente que salta a la vista en el pasaje citado es que se trata de una clasificación ternaria, en lugar de la binaria que hemos usado hasta aquí. Unos entes sólo pueden recibir predicación, otros sólo pueden predicarse y, por último, unos terceros pueden hacer ambas cosas, predicarse y recibir predicados. Los dos primeros tipos son unidireccionales, irrebasa-

\footnotetext{
${ }^{9}$ De hecho, como veremos, lo que se suele verter por "término", esto es, ö $\rho \circ$, no designa en el texto aristotélico una noción genérica que englobaría a los "términos singulares" y a los "términos universales", sino, en todo caso, sólo a estos últimos.

10 J. LUKASIEWICZ, op. cit., pp. 16-17.
} 
bles en algún sentido (por así decir, hacia abajo y hacia arriba), y el último es bidireccional, capaz de asumir las dos funciones de la predicación. Comparando esta tripleta con la dualidad anterior, se entiende que a la categoría de "término singular" le corresponde el primer tipo de entes (es decir, aquellos que sólo pueden recibir predicados), y a la de "término general" la última, la que goza de bidireccionalidad. Dejemos a un lado, por el momento, la segunda clase de entes, aquellos que actúan exclusivamente como predicados. Los ejemplos utilizados por Aristóteles para los tipos que ahora nos interesan (y es notable que para el que hemos pospuesto no se nos dé ningún ejemplo) muestran que, por un lado, aquello que hasta ahora hemos llamado "término singular" designa, en el texto aristotélico, lo que podemos considerar las cosas en sentido estricto, los entes, lo presente, aquello con lo que tratamos, mientras que, por otro, los "términos generales" hacen referencia a las determinaciones o aspectos bajo los cuales aquellos se presentan, son considerados o tratados. La irrebasabilidad de los primeros, su exclusiva receptividad predicativa, guarda relación con ese carácter de "aquello con lo que", con ser el objeto de referencia último de toda conducta en sentido amplio; ellos no son aspectos o determinaciones de otras cosas sino que son el sustrato último de toda cualificación. A su vez, la versatilidad funcional de las determinaciones radica en que éstas no sólo son "aquello bajo lo cual" se considera o se trata algo sino también en que ellas pueden ser consideradas o tratadas bajo algún otro aspecto ${ }^{11}$.

De este modo nuestra cuestión puede reformularse del siguiente modo: ¿por qué Aristóteles prescinde de las "cosas" en la silogística? O, lo que es lo mismo, ¿por qué centra Aristóteles sus análisis en las relaciones entre "determinaciones"? Rechacemos de nuevo toda respuesta que se sustente en la exigencia de la "homogeneidad funcional": la configuración silogística, en efecto, requiere tal homogeneidad, pero ello se debe a que tal configuración es resultado del uso exclusivo de determinaciones.

11 Asimismo, encontramos en el De Interpretatione esta misma clasificación -ahora binaria- y algunos de los ejemplos mencionados, precisamente en el momento en que se comienza a tematizar la dimensión "cantidad" en la que puede modularse el

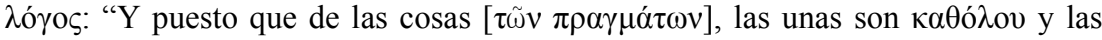

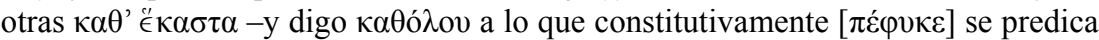
de muchos, y $\kappa \alpha \theta^{\prime}$ ' $́ \kappa \alpha \sigma \tau \alpha$ a lo que no, como el caso de hombre, que es de los $\kappa \alpha \theta$ ó $\lambda$ ov, y de Calias, que es de los $\kappa \alpha \theta^{\prime} \check{~}^{\prime \prime} \kappa \alpha \sigma \tau \alpha-$, necesariamente se manifiesta

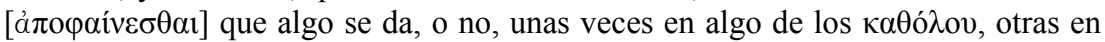
algo de $\operatorname{los} \kappa \alpha \theta^{\prime}$ '́ $\kappa \alpha \sigma \tau \alpha "(7,17 \mathrm{a} 38-17$ b 3). Esta primera distinción interna al ővo $\mu \alpha$ es la base de la distinción de enlace subsiguiente, que distingue los $\lambda$ ó

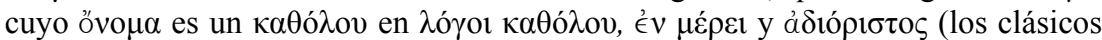
"juicios universales, particulares e indefinidos"). Como se ve, en ella se puede comprobar de nuevo la inseparabilidad lógico-ontológica de la que antes hablábamos, ahora en los términos de "cosas $(\pi \rho \alpha ́ \gamma \mu \alpha \tau \alpha)$ que se predican". 
Para comprender los motivos de esta exclusividad debemos antes dar un cierto "paso atrás".

\section{3. - La estructura dual: algo de algo}

En los primeros capítulos del De Interpretatione, asumiendo una terminología acuñada en los diálogos platónicos, se consideran los aspectos comunes y los privativos de la diversidad funcional que trae aparejada la estructura del $\lambda$ ó $\gamma o \zeta$. Aquello sobre lo que (aquello de que) se predica (el "de qué") es allí designado como ővo $\mu \alpha$, mientras que $\rho \tilde{\eta} \mu \alpha$ corres-

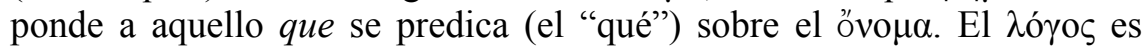
siempre "algo de algo", "qué de qué", $\rho \tilde{\eta} \mu \alpha$ de ővo $\mu \alpha$ o, a raíz de lo ya dicho, determinación de cosa/determinación. En efecto, hemos visto ya como a las determinaciones les es inherente una polivalencia funcional (actuar como $\hat{\rho} \tilde{\eta} \mu \alpha$ y como övo $\mu \alpha$ ), mientras que a las cosas en sentido estricto sólo les cabe ser "aquello sobre lo que", el "de qué", actuar como ővo $\mu \alpha$. A partir de estos análisis podremos entender más en concreto la razón de esta bifuncionalidad de las determinaciones.

$\mathrm{Al}$ ővo $\mu \alpha$ y al $\rho \tilde{\eta} \mu \alpha$ les corresponde, como rasgo común, el significar

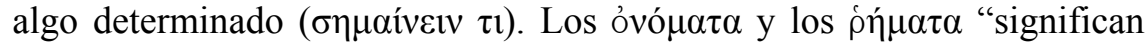
algo unitario" ( $€ v \sigma \eta \mu \alpha i v \varepsilon v v)$, y esto quiere decir, en palabras de Aristóteles: "si hombre es esto, siendo algo el hombre, ello será el ser respecto del hombre". ${ }^{12}$

Significar algo unitario es tener una entidad determinada ${ }^{13}$. En los términos de Categorías esto quiere decir: estar sinonímicamente determi-

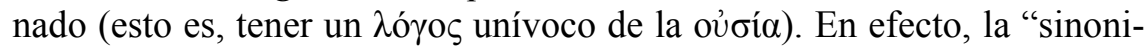
mia" ocurre cuando una determinación se predica unívocamente de varias

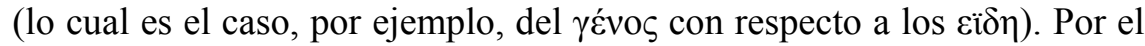
contrario, la "homonimia" es la predicación equívoca de una determinación. En el caso de una homonimia -por así decir- trivial se puede ver cómo todo acto determinativo está estructurado en relaciones sinonímicas: en un uso homonímico puede siempre detectarse una confusión de predicaciones sinonímicas, cuya mera advertencia es capaz de deshacer la

12 Metafisica, IV, 4, 1006a32.

${ }^{13}$ En este nivel de análisis (es decir, en el De Interpretatione) no comparece aún un problema que motiva muchas de las inflexiones del pensamiento griego: el pro-

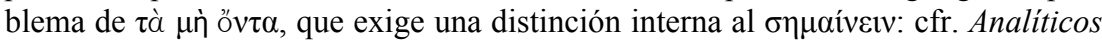
Posteriores, II, 10. Este problema formulado en estos términos sólo puede surgir tras un análisis del fenómeno $\lambda$ ó ${ }^{\circ}$, ámbito dentro del cual, y sólo dentro del cual, tiene sentido decir "si es o no es". Adviértase, por lo demás, que en el texto citado de la Metafísica sí se tiene en cuenta implícitamente esta problemática, como indica la clausula "siendo algo el hombre". 
incorrección ${ }^{14}$. Todo acto determinativo real se apoya, pues, en la exigencia de predicación sinonímica. El ővo $\mu \alpha$ y el $\rho \tilde{\eta} \mu \alpha$ representan, de este

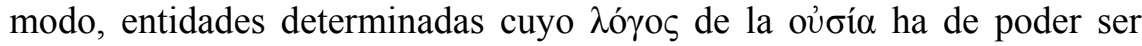
explicitado en cualquier momento. De ahí que otro de sus rasgos comunes sea el de que ninguna de sus partes signifique separadamente: su elementalidad semántica es correlato de su autonomía ontológica ${ }^{15}$. Es esta exigencia sinonímica la que da razón de la polivalencia funcional de las determinaciones: en cuanto que actúan exclusivamente de övo $\mu \alpha$, las cosas -en sentido estricto- están ya en disposición funcional de cumplir con la exigencia de predicar de ellas su oủoía, las determinaciones en cambio, son obligadas a desplazarse de su función determinativa activa al estado funcional pasivo del ővo $\mu \alpha$, esto es, a ser objeto de predicación. La dualidad de funciones de las determinaciones se sustenta así en la exigencia común a ővo $\mu \alpha$ y $\rho \tilde{\eta} \mu \alpha$ de poseer una determinación sinonímicamente regulada.

Pero tratemos ahora de analizar lo específico del $\rho \tilde{\eta} \mu \alpha$, por cuanto es función exclusiva de las determinaciones, con vistas a encontrar las posibles razones del privilegio de estas sobre las cosas en la silogística.

\section{4. - El $\rho \tilde{\mu} \mu \alpha$ en cuanto tal: lógica y ontología}

La primera caracterización que se nos ofrece del $\rho \tilde{\eta} \mu \alpha$ es la siguiente:

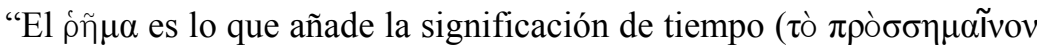

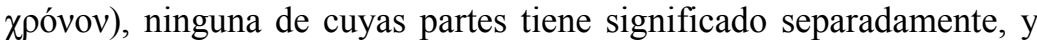
es signo de lo que se dice acerca de otro". ${ }^{16}$

De los dos últimos rasgos ya hemos hablado: el segundo alude a lo que el $\rho \tilde{\eta} \mu \alpha$ tiene de común con el ővo $\mu \alpha$ (la elementalidad semántica) mientras que el tercero nos indica que sólo las determinaciones pueden fungir de $\dot{\rho} \tilde{\eta} \mu \alpha$. Por lo tanto, es la primera característica la que aquí nos

${ }^{14}$ Cfr. Metafísica, IV, 4, 1006a34-1006b5: "En nada difiere si alguien dijera que

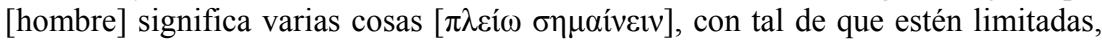

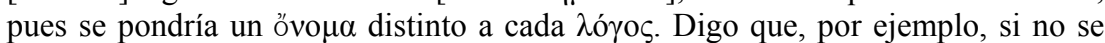
dijera que hombre significa algo unitario, sino muchas cosas [ëv $\sigma \eta \mu \alpha i ́ v \varepsilon v v, \pi 0 \lambda \lambda \grave{\alpha}$

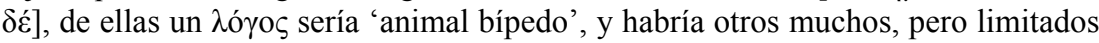

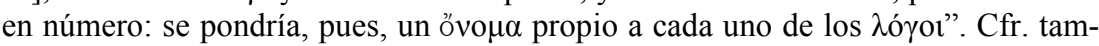
bién Refutaciones sofísticas, 4, 166a15-22; 7, 169a23.

${ }^{15}$ Cfr., para el övo $\mu \alpha$, De Interpretatione, 2, 16a20, y, para el $\rho \tilde{\eta} \mu \alpha, 3,16 \mathrm{~b} 6$. Cfr.,

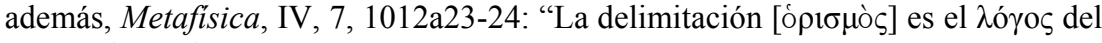
que es signo el ővo $\mu \alpha$ ".

${ }^{16}$ De Interpretatione, 3, 16b6-7. 
interesa. "Añadir la significación de tiempo" es, según las aclaraciones posteriores del texto, poner en juego ciertos "morfemas" que no modifican la semántica concreta del término o de los términos implicados, sino que actúan de manera por así decir "metafrástica", esto es, inciden sobre

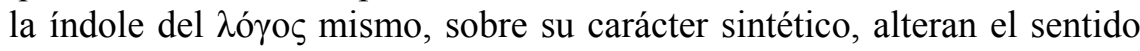
mismo del enlace entre los dos elementos. Llamemos, en consonancia con lo dicho, "sentido" a esta dimensión que no puede reducirse a la "semántica" de los elementos utilizados; fijemos a su vez "significado" (y "semántica") para el rasgo común de la exigencia de determinación sinonímica que es inherente a todo ővo $\mu \alpha$ y a todo $\rho \tilde{n} \mu \alpha$.

Así pues, las diferencias que introduce específicamente el $\rho \tilde{\eta} \mu \alpha$ son diferencias de sentido. En efecto, la diferencia entre "sanó" y "sanaba" no refiere al significado de la determinación flexionada sino que es una diferencia de sentido, relativa a la modulación del propio enlace. De igual modo, la diferencia entre "un hombre es blanco" y "un hombre no es blanco" no atañe a los elementos puestos en juego, sino a su combina-

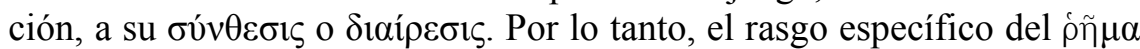
es el de añadir diferencias relativas a la combinación de los elementos semánticos, determinaciones del $\lambda$ ó ${ }^{\circ} \varsigma$, cuyo "grado cero" sería la forma “...es...". En efecto, en el griego antiguo tales morfemas metafrásticos pueden ser asumidos por un término semánticamente nulo, que entonces ejerce la función de "cópula" y se "limita" a hacerse cargo de las determinaciones referentes a la articulación misma del ővo $\mu \alpha$ y el $\rho \tilde{\eta} \mu \alpha$. Nos referimos al verbo Eĩval (que ejerce predominantemente esta función, pese a que sea a menudo relevado por otros verbos cuya semántica es no obstante indudable) ${ }^{17}$.

Esto mismo es reconocido por Aristóteles allí donde trata de indicar cómo las categorías no son "especies" de un género sino "flexiones" inmediatas del verbo "ser", "sentidos" en los que éste se dice:

"Así pues, puesto que de los predicados, unos significan el qué es, otros el cuál, otros el cuánto, otros el con respecto a qué, otros el hacer o el padecer, otros el dónde, otros el cuándo, el ser ( $\tau$ c̀ cĩval) significa lo mismo que cada uno de ellos: pues en nada difieren 'el hombre es convaleciente' y 'el hombre convalece', ni 'el hombre es caminante o talador' de 'el hombre camina o tala', y de modo semejante en los demás casos". ${ }^{18}$

\footnotetext{
${ }^{17}$ Conviene, sin embargo, matizar esta última afirmación, dado que en estos textos nos encontramos en el proceso de consumación de este estado de cosas. Es decir, la autonomización de la cópula es un hecho lingüístico del griego en este estadio, pero todavía no constituye una obviedad (como sí lo será en el Helenismo). Cfr. F. MARTÍNEZ MARZOA, Ser y Diálogo, Madrid, Istmo, 1996; cap. 3.

18 Metafísica, V, 7, 1012a23-30.
} 
En los ejemplos propuestos se ve cómo es indiferente que los morfemas metafrásticos sean asumidos por la determinación que se predica (por así decir, verbalizándola) o que sean recogidos por el Eĩval que enlaza el "qué" y el "de qué". En ambos casos, el "añadir la significación de tiempo" no se modifica, del mismo modo que no se modifica la tipología categorial en que se encuadra la predicación. Precisamente por eso la tipología categorial de los predicados remite a otros tantos "sentidos" del ser: cada organización de significados en torno a una categoría hace relevante una forma distinta de enlace, que se plasma en las partículas interrogativas de las que son respuesta (¿qué es?, ¿cuánto es?, ¿cómo es?, etc. $)^{19}$. La autonomización de los morfemas metafrásticos en el verbo "cópula" no comporta diferencia alguna de sentido ${ }^{20}$.

Asimismo, ya en el De Interpretatione aparece expresada la especificidad del $\rho \tilde{\eta} \mu \alpha$ en los términos de "añadir el ser y el no ser": "Así pues, dichos por sí mismos, los $\rho \eta ́ \mu \alpha \tau \alpha$ son ỏvó $\mu \alpha \tau \alpha$ y significan algo (...) pero aún no si es o no es". ${ }^{21}$

Lo específico de los $\rho \eta ́ \mu \alpha \tau \alpha$ no es su carácter significativo (el cual lo poseen "dichos por sí mismos", de manera aislada, es decir, no en su función lógica) sino la posición del enlace, el añadir "si es o no es X (esto es, el significado que sea)"; tan sólo en la combinación surge lo peculiar de ellos. Por otro lado, el mismo pasaje confirma la no semanticidad de las diferencias de sentido, diciendo a continuación:

“en efecto, el ser o no ser (

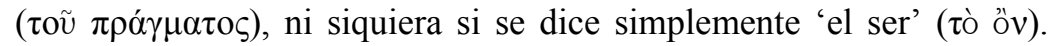

\footnotetext{
19 "En las categorías se expresa, pues, los distintos significados de 'ser', y no cabe buscar otra razón o fundamento de ello fuera de la propia naturaleza de las categorías. Cualquier otra circunstancia resultará irrelevante o, con otras palabras, meramente accidental al respecto. Así, es meramente accidental al respecto el que aparezca o deje de aparecer el verbo 'ser' en cada caso. Cuando decimos que «el hombre es(tá) paseando», el predicado comporta una significación de 'ser' («hacer», poîein), pero ello no se debe a la circunstancia de que en tal predicación aparezca la cópula 'es(tá)'. La presencia de la cópula es una mera contingencia lingüística, algo meramente accidental (en el sentido de «coincidencia»), algo que podría no suceder y que de hecho no sucede cuando expresamos lo mismo diciendo «el hombre pasea». Y sin embargo, también en este caso el predicado 'pasea' comporta y actualiza un significado propio de 'ser', aun cuando el 'es' no aparezca en la expresión gramatical de la predicación” (T. CALVO MARTÍNEZ, «Releyendo a Aristóteles: ¿Qué, y de qué, son por sí las categorías?», Revista de Filosofia, 3. a época, vol. VIII (1995), núm. 13, p. 83).

${ }^{20}$ El que Aristóteles tenga que poner de relieve esto mismo es síntoma de la "todavía no obviedad de la cópula" que mencionábamos en una nota anterior.

${ }^{21}$ De Interpretatione, 3, 16b20-21.
} 
Pues ocurre que éste no es en sí mismo nada, sino que añade la signi-

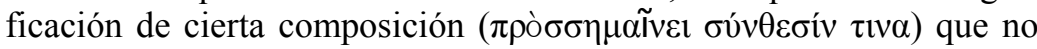
es pensable sin los componentes" (16b22-25).

Donde se ve cómo la cópula, el 'ser', consiste únicamente en ese "añadir la significación" que es rasgo privativo del $\rho \tilde{\eta} \mu \alpha$ en cuanto tal, es decir, no en cuanto este o aquel (los cuales se distinguen, más bien, por sus diferencias semánticas) ${ }^{22}$.

A su vez, las precisiones terminológicas con las que arranca el primer capítulo de los Analíticos Primeros se hallan en consonancia con lo expuesto. Al hablar de $\pi \rho \tau_{\tau} \alpha \sigma 1 \varsigma$, Aristóteles neutraliza las dos funciones resaltadas en el De Interpretatione, concibiendo a ambos elementos, indistintamente, como öpor (algo así como "lindes", "delimitaciones"; de donde el tradicional "términos"). La $\pi \rho o ́ \tau \alpha \sigma \iota \varsigma$ se descompone en dos entidades de mismo rango porque los elementos que combina son siempre determinaciones, cuya versatilidad se expresa en la desaparición de la distinción funcional. Los őpor representan aquí las delimitaciones en las que se descomponen los $\lambda$ ó $\gamma o 1$ analizados, precisamente porque la funcionalidad específica del $\dot{\rho} \tilde{\mu} \mu \alpha$ es asumida separadamente por el "...es...".

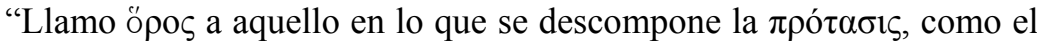
predicado y aquello sobre lo que se predica, con la adición del ser o del no ser". 23

22 En paralelo con esto queremos hacer resaltar que a la propia cuestión de la combinación, de lo específico del $\rho \tilde{\eta} \mu \alpha$, se une la de la verdad o la falsedad, tal como sucede en El sofista platónico. En efecto, "la falsedad y la verdad corresponden a

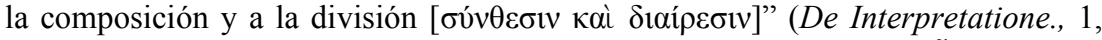
16a12), lo que, según el texto citado anteriormente, es la función del cĩval ("añadir la significación de alguna composición"): "Señal de esto es lo siguiente, que 'hirco-ciervo' significa algo, pero no es aún verdadero o falso, si no se le añade el ser o el no ser, sin más o según el tiempo" $(1,16$ a12-18). Aquí se ve cómo "añadir el ser o el no ser" no tiene que ver con ninguna presunta función existencial del Eivol (frente a la copulativa), sino con poner lo designado (en este caso, 'hirco-ciervo') en relación con alguna determinación (aquí indeterminada), lo cual redundará en la verdad de lo mostrado (si se dice lo que es como siendo o lo que no es como no siendo) o en su falsedad (si se dice lo que es como no siendo o lo que no es como siendo). Cfr. Sofista, 263b; Metafísica, IV, 7, 1011b25-29. Por lo demás, desviar este pasaje, debido a la aparición de "hirco-ciervo", hacía la problemática de los "términos vacíos" es otra muestra de la predisposición a no ver en estas obras problemas que excedan los propios planteamientos.

${ }^{23}$ Analíticos Primeros, I, 1, 24b16. Podría resultar por lo demás curioso que el verbo utilizado por Aristóteles seguidamente, en la exposición de las figuras, sea, pese a

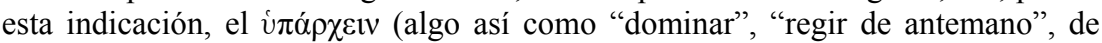


En este modo de expresarse se encuentra anulada la diferencia funcional ővo $\mu \alpha-\rho \tilde{\eta} \mu \alpha$ mediante la autonomización del elemento sintético y la fijación de una única designación para ambos componentes, que ya sólo difieren por sus rasgos semánticos. La eliminación de las diferentes funciones se suple, en coherencia con lo expuesto, mediante el recurso a la "cópula".

La especificidad del $\rho \tilde{\eta} \mu \alpha$, por lo tanto, no consiste en algún rasgo de índole semántica (lo cual corresponde más bien a que sea este o aquel $\tilde{\eta} \mu \alpha$, a que sea "sanó" o "enfermó", pero no es propio de aquello que hace $\hat{\rho} \tilde{\eta} \mu \alpha$ al $\hat{\rho} \tilde{\eta} \mu \alpha$, del $\hat{\rho} \tilde{\eta} \mu \alpha$ en cuanto tal) sino en aportar el enlace mismo y determinarlo en un aspecto u otro mediante las flexiones morfemáticas aludidas; en otras palabras, lo específico del $\rho \tilde{\eta} \mu \alpha$, de que haya $\rho \tilde{\eta} \mu \alpha$ en general, es la $\sigma u ́ v \theta \varepsilon \sigma i \varsigma$, el "...es...” (o la modulación que sea), el ser,

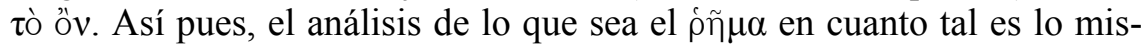
mo que el análisis de lo que sea el ser en cuanto tal ( $\tau$ ò ôv ñ ồ ${ }^{24}$. De este modo, el examen del fenómeno $\lambda$ ó $\gamma$ o de imprimir al proyecto aristotélico su carácter "ontológico", de conducirlo hacia la tematización de la posibilidad de "un cierto saber que contempla el ser en cuanto ser". Lejos de contraponerse la lógica y la ontología, sería el inicial arranque lógico (el "giro lógico") el que comportaría la caracterización ontológica del proyecto, la fijación de $\tau$ ò ôv como objeto de investigación ${ }^{25}$.

De este modo, si sólo las determinaciones son capaces de fungir de $\hat{\rho} \tilde{\mu} \mu \alpha$, esto es, si las determinaciones no en cuanto que son esta o aquella sino en cuanto tales son lo mismo que los $\rho$ í $\mu \alpha \tau \alpha$, ello quiere decir que el estudio de sus relaciones "puras", es decir, de sus relaciones en cuanto determinaciones, es lo mismo que poner de relieve lo específico del enlace. La investigación de las formas de conexión que pertenecen a las determinaciones qua determinaciones es, por lo tanto, un paso hacía la

donde la traducción convencional "darse en"). Una razón para ello podría ser, como ha sido muchas veces señalado, la rección de í $\pi$ ó $\chi \varepsilon \varepsilon v$, que distingue nítidamente entre el qué (Nominativo) y el de qué (Dativo): algo 1 es algo $2=$ algo 2 se da en algo 1.

${ }^{24}$ Cfr. F. MARTÍNEZ MARZOA, «Comentario a: Aristóteles, De Interpretatione, 1-3», en: Á. ÁlVAREZ GÓMEZ / R. MARTÍNEZ CASTRO (coord.), En torno a Aristóteles. Homenaje al profesor Pierre Aubenque, Santiago de Compostela. Universidade, Servicio de Publicaciones e Intercambio Científico, 1998, pp. 119-129.

${ }^{25}$ La identidad de ambas investigaciones es planteada aporéticamente en Metafísica, III, 1, 995b6-10; 2, 996b25-997a14. La "resolución” de esta aporía o, más propiamente, la profundización en ella, se realiza en Metafísica, IV, 3; cfr., en especial,

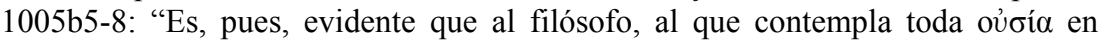

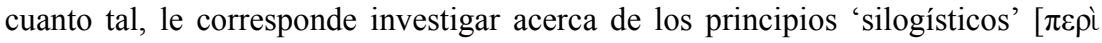
$\tau \tilde{\omega} \nu \sigma v \lambda \lambda \sigma \gamma \imath \sigma \tau \iota \kappa \tilde{\omega} v \alpha \dot{\rho} \rho \tilde{\omega} v] ”$. 
investigación acerca del ser en tanto que ser. Bien es cierto que Aristóteles no señala nada de esto en los tratados "lógicos", es decir, que no hay allí mención temática de algo así como "el ser en cuanto ser", pero ello puede comprenderse por cuanto las investigaciones que tematizan la problemática inscrita en esa denominación (las investigaciones, digamos, metafísicas) suponen como resultado la tematización del fenómeno $\lambda$ ó (por eso hemos dicho que el estudio de las relaciones puras entre determinaciones es un "paso" hacia el saber del ser en cuanto ser: éste último consiste en la reflexión sobre los resultados de aquel) ${ }^{26}$. En otras palabras: la indagación y por lo tanto la relevancia de la estructura del $\lambda$ ó $\gamma o \varsigma$ hace aflorar una yuxtaposición de dimensiones (por ejemplo, cualidad, cantidad, modalidad) que, una vez desplegadas, reenvían al problema de su unidad (la unidad de los sentidos del ser: ser como verdad y falsedad, ser

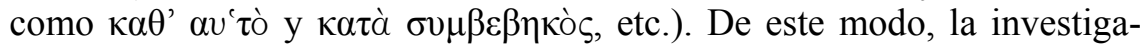
ción "lógica" actúa a modo de antesala para la investigación "metafísica", pero ello en tanto que aquella suministra la problemática que será objeto de reflexión para aquella.

\section{5. - Las razones de la limitación: la fundación de la onto-logía}

Teniendo en cuenta lo dicho hasta ahora, estamos en condiciones de entender los motivos de la decisión aristotélica. Dentro de una interpretación tradicional, decíamos, la decisión aparece necesariamente como arbitraria, pero dentro de una perspectiva como la aquí desarrollada puede entenderse como el primer paso en el proceso de fundamentar e iniciar la

\footnotetext{
${ }^{26}$ Del mismo modo, hemos visto ya como en el texto anteriormente citado de los Analíticos Primeros no se nos proporcionaba ningún ejemplo de los entes del segundo tipo, aquellos que sólo funcionaban como predicados. Ahora podemos entender que tales "entes" son determinaciones del $\rho \tilde{\eta} \mu \alpha$ en cuanto tal o, lo que es lo mismo, determinaciones del sentido, del $\lambda o ́ \gamma o \varsigma$, de $\tau$ ò ôv. Esto mismo es reconocido por J. LUKASIEWICZ (op. cit., p. 16) en su explicación de ese pasaje: "Con respecto a esa clase de cosas no se da ejemplo alguno, pero es claro que Aristóteles se refiere a lo que es más universal, como el ser, tò ôv". A su vez, D. ROSS p. 384- los identifica en su comentario con "los más altos universales, las categorías". Que a este nivel no haya ejemplos de esta clase y que no haya mención temática de "el ser en cuanto ser" son aspectos de lo mismo. El análisis de lo específico del $\lambda$ ó $\gamma_{o} \varsigma$ hace aflorar determinaciones que son específicas de los $\rho \eta ́ \mu \alpha \tau \alpha$, determinaciones relativas al enlace que son aquel tipo de "entes" cuyo comentario habíamos dejado pospuesto. Los "entes" que sólo se predican, que no pueden ser "ovo $\mu \alpha$, son las determinaciones específicas del $\rho \tilde{\eta} \mu \alpha$, aquellas que hacen $\rho \tilde{\eta} \mu \alpha$ al $\hat{\rho} \tilde{\eta} \mu \alpha$, aquellas que se dicen en todo $\hat{\eta} \tilde{\mu} \alpha$ en cuanto tal, de donde el problema central en Aristóteles- de cómo es posible un discurso, un "saber", que verse sobre esta suerte de "entidades" no tematizables.
} 
filosofía como ontología, como saber del ser en cuanto ser. Así pues, la exclusión de las cosas (de los "términos singulares") sería consecuencia del inicial planteamiento (onto-)lógico del pensamiento aristotélico ${ }^{27}$. Es la decisión de investigar el $\lambda o ́ \gamma o \zeta$ en cuanto tal lo que obliga a centrar la cuestión en el $\rho \tilde{\eta} \mu \alpha$ en cuanto tal y con ello en la determinación en cuanto tal, y todo ello es lo que llevará a formular el problema filosófico como problema del ser en cuanto ser.

Así pues, el uso de variables en la silogística asume la "limitación" de representar sólo determinaciones debido a que se inserta en un proyecto más global como es el de subrayar aquello que hace $\lambda$ ó $\gamma \circ \varsigma$ al $\lambda o ́ \gamma o \varsigma$, las características específicas de los enlaces. Por ello, en vez de utilizar ejemplos concretos (que sólo se darán en el caso de modos no válidos y de tal suerte que el "silogismo" compuesto con ellos sea "materialmente" verdadero), Aristóteles recurre al empleo de variables, que sólo tienen en cuenta la condición general de todo ővo $\mu \alpha$ y $\rho \tilde{\eta} \mu \alpha$, el "significar algo unitario", es decir, la exigencia sinonímica, y permiten mostrar, en tanto que ellas representan las formas "puras" de determinación, las correspondientes relaciones "puras" entre las mismas.

Así, si tomamos por ejemplo los modos válidos de la primera figura, podemos extraer las siguientes "leyes" determinativas: una determinación hereda las determinaciones esenciales de sus determinaciones esenciales (bArbArA); una determinación excluye esencialmente aquello que excluyen sus determinaciones esenciales (cElArEnt); en una determinación coinciden las determinaciones esenciales de sus coincidencias (dArII); en una determinación no se da por coincidencia aquello que es excluido esencialmente por sus coincidencias (fErIO). Como se ve, los modos válidos silogísticos constituyen, a partir de esta lectura, propiedades inherentes a toda determinación en cuanto tal.

La sustitución de ejemplos concretos por variables comporta, por lo tanto, dos ventajas inmediatas: por un lado, bloquea las distorsiones "semánticas" del análisis centrándolo en las relaciones puras de las determinaciones en cuanto tales, y, por otro, al no indicar más que la forma pura del "significar algo" posibilita cumplir con la unidad semántica de cada determinación, alejando así toda confusión "homonímica". Si volvemos por un momento al texto anteriormente citado de W. \& M. Kneale apreciaremos ya una nueva diferencia a partir de lo expuesto:

${ }^{27}$ De ahí el relativo acuerdo antes señalado en una nota anterior con la afirmación de L. VEGA GONZÁLEZ: "es obvio que el interés aristotélico por los términos generales del lenguaje de la silogística obedece a la atención que le merece la ciencia demostrativa" (op. cit., p. 192); pues precisamente es el contexto de la "demostración” el que pone de relieve de un modo neto las propiedades del $\lambda$ ó

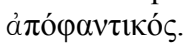


"Aristóteles se sirve de letras como términos-variables (...) bajo la sola condición de que los espacios indicados por la misma letra sean rellenados por el mismo término en todos y cada uno de los enunciados que entran en juego en una argumentación dada". ${ }^{28}$

Lo que en esta explicación tiene la índole de una condición más o menos arbitraria, ha adquirido en la nuestra un carácter vinculante objetivo: cada variable designa uno y el mismo "término" en cada momento argumentativo debido a la condición formal-general de todo övo $\mu \alpha$ y $\dot{\rho} \tilde{\mu} \mu \alpha$, la exigencia de sinonimia, que de otro modo sería homonímicamente violada. El que se cumpla sólo con la unidad semántica de cada determinación no es ya una condición que se añada al uso de variables, sino la razón de ese mismo uso.

\section{2. - La "cantidad" de las variables aristotélicas}

\section{1. - El supuesto de la generalidad del $\tilde{\rho} \tilde{\mu} \mu \alpha$ en la designación alfabética}

Si atendemos ahora a la mera denominación de las variables de cada figura veremos que en ella opera un supuesto de "anterioridad del predicado" que distribuye cada una de las letras-variables con arreglo a un criterio funcional: a aquello que sólo opera como $\rho \tilde{\eta} \mu \alpha$ le corresponde la letra primera, la segunda a la determinación que vaya a ejercer tanto de

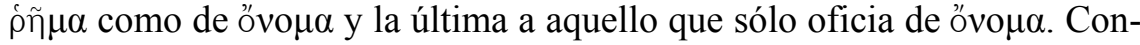
cretamente:

- Primera figura: A se dice de/ se da en B y B se dice de/ se da en C, por tanto, $\mathrm{A}$ se dice de/ se da en $\mathrm{C}$. A = extremo mayor (sólo $\rho \tilde{\eta} \mu \alpha) ; \mathrm{B}=$ término medio (ővo $\mu \alpha$ y p̃ $\mu \alpha$ ); $\mathrm{C}=$ extremo menor (sólo ővo $\mu \alpha$ ).

- Segunda figura: $\mathrm{M}$ de / en $\mathrm{N}$ y de / en O; por tanto, $\mathrm{N}$ de / en O. M $=$ término medio (sólo $\hat{\rho} \tilde{\eta} \mu \alpha) ; \mathrm{N}=$ extremo mayor (ővo $\mu \alpha$ y $\dot{\rho} \tilde{\mu} \mu \alpha) ; \mathrm{O}=$ extremo menor (sólo ővo $\mu \alpha$ ).

- Tercera figura: P y R de / en S, por tanto, P de / en R. P = extremo mayor (sólo $\rho \tilde{\eta} \mu \alpha)$; $\mathrm{R}=$ extremo menor (o’vo $\mu \alpha$ y $\hat{\rho} \tilde{\eta} \mu \alpha) ; \mathrm{S}=$ término medio (sólo ővo $\mu \alpha)^{29}$.

El orden alfabético de las variables corresponde a la función predicativa que representan, de modo que la primacía en la relación serial es

${ }^{28}$ W. KNEALE / M. KNEALE, op. cit., p. 58.

${ }^{29}$ Seguimos aquí la transcripción de letras griegas que hace M. CANDEL en su traducción al castellano de los Analíticos Primeros (Gredos), tratando de respetar el orden alfabético que emplea Aristóteles. 
relativa al papel activo que asuman. Así, en la primera figura, el término medio es representado por la letra intermedia, por cuanto es ővo $\mu \alpha$ del extremo mayor y $\hat{\rho} \tilde{\eta} \mu \alpha$ del menor ( $=\mathrm{EM}>\mathrm{Tm}>\mathrm{Em})$. En la segunda y la tercera, sin embargo, asume la primera y la última letra, respectivamente, dado su carácter exclusivamente activo (en la segunda; $=\mathrm{Tm}>$ 'EM $\wedge$ Em') o exclusivamente pasivo (en la tercera; = 'EM $\wedge$ Em' $>\mathrm{Tm}$ ). Del mismo modo, en todas las figuras el extremo mayor siempre es representado por una letra anterior a la del extremo menor, dado que en la conclusión siempre se predica el mayor del menor $(=\mathrm{EM}>\mathrm{Em})^{30}$.

¿A qué obedece esta "anterioridad" del $\rho \tilde{\eta} \mu \alpha$ frente al ővo $\mu \alpha$ que rige como supuesto en la construcción de las figuras silogísticas? Aquí hallamos operando un criterio de jerarquía entre determinaciones, que asume que aquello que es $\dot{\rho} \tilde{\mu} \alpha$ es anterior a, más general que o se halla incluido en (como se quiera decir) el ővo $\mu \alpha$. Por lo tanto, el supuesto para la denominación es el de la mayor generalidad del $\hat{\rho} \tilde{\mu} \mu \alpha$ respecto del övo $\mu \alpha(=\mathrm{R}>\mathrm{O})$. De este modo, la posibilidad *AE en la primera figura no es concluyente dado que la exclusión entre $\mathrm{B}$ y $\mathrm{C}$ no tiene por qué afectar a la presencia de A en C: en efecto, siendo A más general que B, siendo una determinación esencial suya, puede abarcar a $\mathrm{C}$ (caso de animal, hombre y caballo, respectivamente) o no (caso de animal, hombre y piedra). Igualmente, la posibilidad *AA en la segunda tampoco es necesariamente concluyente, ya que, siendo $\mathrm{M}$ más general que $\mathrm{N}$ y que $\mathrm{O}$, puede ocurrir que $\mathrm{N}$ se dé universalmente en $\mathrm{O}$ (entidad-animal-hombre) o que no (entidad-animal-número), es decir, $\mathrm{N}$ puede o no pertenecer a la misma cadena jerarquizadora de $\mathrm{O}$. Ahora veamos un ejemplo de la tercera figura: la posibilidad *AE no concluye a su vez, puesto que, siendo $\mathrm{P}$ más general que $\mathrm{S}$, la exclusión esencial de $\mathrm{R}$ y $\mathrm{S}$ no determina qué presencia tenga $\mathrm{P}$ en $\mathrm{R}$ (puede darse esencialmente, por ejemplo, animal-caballo-hombre, o no, como en animal-inanimado-hombre) ${ }^{31}$.

De todo esto se desprende que a la base del aparato silogístico se halla operando, al menos en principio, en su constitución formal, en la producción de la configuración de cada figura, un esquema aparentemente "arbitrario" de jerarquización funcional de las determinaciones-variables. "Arbitrario" es, en efecto, este esquema para una interpretación tradicio-

${ }^{30} \mathrm{Cfr}$., respecto de las extensiones de los términos en cada figura, J. MARITAIN, El orden de los conceptos, Buenos Aires, Club de Lectores, 1958, pp. 260-262; C. NEGRO, La sillogistica di Aristotele, Bologna, Patrón, 1967, p. 146; M. MIGNUCCI, La teoria aristotelica della scienza, Firenze, G.C. Sansoni editore, 1965, pp. 220-221.

${ }^{31}$ Los ejemplos concretos han sido tomados del texto aristotélico y representan, respectivamente, el orden serial de las variables. 
nal, pues "no es posible determinar relaciones extensionales entre variables". 32

$\mathrm{Y}$ es que, en efecto, "sólo podemos comparar las extensiones de términos concretos, no de variables". ${ }^{33} \mathrm{Y}$, sin embargo, como veremos, es esta nueva arbitrariedad la causa tanto de la distribución de las figuras como de que sean tres y sólo tres.

\section{2. - Generalidad del $\rho \tilde{\eta} \mu \alpha$ y forma lógica}

Para poder entender los motivos de esto hemos de reparar en que el que este esquema actúe como supuesto no quiere decir que sea aplicable a los análisis concretos de cada modo, pues como veremos este supuesto sólo es válido para los $\lambda$ ó les afirmativos" (A), aquellos que vinculan esencialmente una determinación a otra. Las razones de ello son evidentes a partir de los pasajes en los que Aristóteles explicita las "capacidades" de estas formas lógicas (cfr. Analíticos Primeros, I, 2).

En efecto, la forma $E$ (universal negativa) es capaz de transponer bidireccionalmente y sin alteración las funciones de ővo $\mu \alpha$ y $\rho \tilde{\eta} \mu \alpha$ de sus términos ( $\mathrm{E} \leftrightarrow \mathrm{E}^{\prime}$ ), es decir, el ővo $\mu \alpha$ puede pasar a cumplir la función de iñ $\mu \alpha$ y éste la de aquel sin que se produzca modificación alguna en el enlace. En otras palabras, si una determinación excluye de un modo esencial a otra, la inversa ha de ser a su vez verdadera, ya que de existir alguna vinculación la exclusión primera no sería efectiva. La forma E implica, por lo tanto, una mutua exclusión esencial entre las determinaciones que relaciona. Así pues, en ella es indiferente decir cuál es el ővo $\mu \alpha$ y cuál el ¡ं̃ $\mu \alpha$, con lo que no hay lugar para decidir acerca de la mayor generalidad de uno u otro. La forma E, por lo tanto, no cumple con el supuesto de la mayor generalidad del $\rho \tilde{\eta} \mu \alpha$ sobre el ővo $\mu \alpha$, es decir, no establece gradaciones jerárquicas entre determinaciones. De ahí que en la segunda

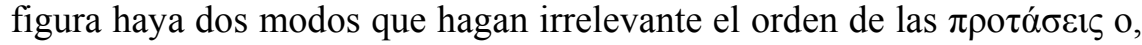
lo que es lo mismo, que indiferencien los papeles de extremo mayor y menor (cEsArE y cAmEstrEs): la mutua exclusión que supone la forma $\mathrm{E}$ posibilita una conclusión por cElArEnt que puede ser traspuesta.

De igual modo, la forma I (particular afirmativa) es bidireccionalmente invertible sin alteración ( $\mathrm{I} \leftrightarrow \mathrm{I}$ '). La razón de ello es la de que la coincidencia de una determinación en otra implica, al menos, la misma relación a la inversa. Si no hubiera tal bidireccionalidad la primera relación no sería tal. Que una determinación coincida con otra supone un

\footnotetext{
32 J. LUKASEWICZ, op. cit., p. 33.

${ }^{33}$ G. PATZIG, Aristotle's theory of the syllogism, Dordrecht, D. Reidel, 1968; p. 98.
} 
"punto de contacto" que ha de tener su expresión en la capacidad de trasposición funcional. Por lo tanto, de modo similar a E, la forma I tampoco cumple con el supuesto de la mayor generalidad del $\rho \tilde{\eta} \mu \alpha$. La coincidencia de una determinación en otra no decide acerca de la jerarquización entre ellas. La forma I posibilita así otro caso de indiferencia entre los papeles de extremo mayor y menor, esta vez en la tercera figura (modos dAtIsI y dIsAmIs).

Sin embargo, la tercera capacidad analizada por Aristóteles sí que establece una relación asimétrica entre el ővo $\mu \alpha$ y el $\rho \tilde{\eta} \mu \alpha$ : se trata de la capacidad de la forma A de trasponer sus funciones a costa de "particularizar" el enlace, de "accidentalizar" la relación entre las determinaciones $(\mathrm{A} \rightarrow \mathrm{I}$ '). Esta capacidad, asimétrica y unidireccional, sí cumple con la mayor generalidad del $\rho \tilde{\eta} \mu \alpha$, de modo que la inversión de papeles deviene una mera coincidencia entre las determinaciones. La inclusión esencial de una determinación en otra no supone la inversa, sino una presencia incidental de ésta en aquella. 'Animal', como determinación esencial de 'hombre', es un aspecto más general o anterior que éste, con lo que, si invertimos la afirmación, éste sólo se da fácticamente en aquel. Así pues, la forma $\mathrm{A}$ es la única que establece, de manera positiva, grados jerárquicos entre determinaciones ${ }^{34}$.

Pero entonces, si sólo la forma A cumple con aquel supuesto que se halla a la base de la peculiar constitución de cada figura, podemos decir que es esa misma forma la que constituye la posición privilegiada a partir de la cual se construyen las distintas figuras. El supuesto anteriormente detectado de la mayor generalidad del $\rho \tilde{\eta} \mu \alpha$ consiste, por lo tanto, en la presuposición de primacía de una forma (A) sobre las demás, y tal privilegio es lo que proporciona el criterio de construcción de las tres figuras silogísticas.

\section{3. - Razones para "omitir" la cuarta figura}

El análisis precedente nos permite, a su vez, entender las razones de otra omisión aristotélica relevante para la tradición posterior: la ausencia de una cuarta figura. En efecto, las únicas razones de peso que se puede dar acerca de tal ausencia se sustentan en las relaciones extensionales que

${ }^{34} \mathrm{La}$ forma $\mathrm{O}$, no siendo invertible de modo alguno, no decide acerca de la jerarquización de determinaciones. Por el contrario, su falsedad sí que decidiría, ya que, por contradicción, establece la verdad de la forma A. Sin embargo, no es tan sencillo, pues a su vez la falsedad de O (por subcontrariedad) decide la verdad de I donde no hay gradación. Quizá esta doble condición de O (que en todo caso queda impensada por parte de Aristóteles) es lo que está a la base de su doble formulación ("No todo" y "Algún... no"). 
se dan entre las variables ${ }^{35}$. El criterio de la extensión o generalidad del término medio, en efecto, excluye que haya otra configuración que las tres mencionadas por Aristóteles: "el término medio es o de una extensión intermedia o el más o el menos extenso de los tres términos". ${ }^{36}$

La posibilidad de una cuarta figura (Tm de EM; Em de Tm; luego EM de Em) dependería de que se asumiera, en palabras de Ross, otro fundamentun divisionis: la posición del término medio. ${ }^{37}$ Ahora bien, resulta que, si atendemos ahora a las reglas de construcción de las figuras que hemos relacionado con la jerarquía extensional de las variables, veremos que estas son violadas por la mera forma abstracta de la cuarta figura. En efecto, el esquema de la cuarta figura es formalmente inconstruible según las reglas de anterioridad predicativa que rigen la configuración serial de las variables. Cualquiera de las seis posibilidades de denominación de las variables que se nos ofrecen bajo esta figura contraviene la ley de distribución serial por la simple razón de que la mera forma abstracta ni siquiera la cumple: si Tm se predica de EM (= Tm $>$ EM) y Em de $\operatorname{Tm}(=\mathrm{Em}>\mathrm{Tm})$, entonces, como es obvio, ocurrirá que Em $>$ EM, lo cual contradice la conclusión "EM se predica de Em" (esto es, $\mathrm{EM}>\mathrm{Em})$.

Por lo tanto, no hay omisión fáctica de la cuarta figura; ella es omitida porque su propia posibilidad contraviene los supuestos que rigen la construcción aristotélica. De este modo, Ross acierta al señalar que el mero planteamiento de la posibilidad de una cuarta figura supone un nue-

35 La explicación "genética" de I. M. BOCHENSKI, que Lukasiewicz acepta como "la más probable", consiste en afirmar que el texto de Analíticos Primeros I, 7 y de II, 1 (en dónde aparecen -supuestamente- ejemplos de silogismos de la "cuarta figura") es de redacción posterior al de I, 4-6. Esta solución, sin embargo, como toda explicación genética, depende de una interpretación previa, en donde verdaderamente se decide la cuestión. La asunción previa que yace a la base de esta explicación de Bochenski es la no incompatibilidad de la cuarta figura, de donde se sigue la imposibilidad de una redacción unitaria. Ahora bien, esta solución, así planteada, deja sin explicar las razones de la omisión aristotélica de la cuarta figura en la primera redacción o las del no tratamiento sistemático de la misma en la posterior.

36 O. HAMELIN, Le système d'Aristote, Paris, J. Vrin, 1985; p. 184.

${ }^{37}$ Cfr. W. D. Ross, Aristóteles, Buenos Aires, Charcas, 1981, p. 57: "Como consecuencia de tratar las premisas desde el punto de vista de la extensión, Aristóteles no reconoce la cuarta figura. Si su fundamentum divisionis de las figuras hubiera sido la posición del término medio, habría reconocido como cuarta posibilidad el caso donde es predicado en la premisa mayor y sujeto en la menor. Pero su fundamentum divisionis es la extensión del término medio en comparación con los extremos y entonces no hay más que tres cosas posibles: puede ser más extenso que uno y menos que el otro, o más extenso que ambos, o bien menos extenso que uno y que otro". 
vo fundamentun divisionis, un diferente criterio constructivo. En efecto, es la primacía de la forma $\mathrm{A}$, como hemos visto, lo que nos permite comprender de manera positiva las razones de la omisión aristotélica de la cuarta figura. La posibilidad de una figura tal no es tenida en cuenta por Aristóteles, por más que pueda concluirse "lógicamente" por medio de ella. Su rendimiento "lógico" no puede ponerse en duda y es de hecho posible por las capacidades de inversión que poseen las formas lógicas. Ahora bien, no es esta corrección "lógica" lo que Aristóteles analiza. Por lo tanto, el desarrollo histórico posterior de la problemática de la posibilidad de la cuarta figura ha de ponerse en relación inversa con la asunción de ese supuesto que para Aristóteles va de suyo, el de una jerarquización de las determinaciones que implica a su vez la primacía de una forma (A) sobre las demás. El planteamiento, ausente en Aristóteles, de la posibilidad de una cuarta figura está directamente relacionado con la desaparición de ese supuesto. No es que Aristóteles de facto la omita sino que no puede no hacerlo; la triada de figuras es de iure la única posible dentro del planteamiento aristotélico, pues sus fines difieren del mero rendimiento de una herramienta ${ }^{38}$.

\footnotetext{
${ }^{38}$ G. PATZIG (op. cit.) llega a unas conclusiones similares a las nuestras, aunque dentro de una óptica totalmente diferente: "Aristóteles no admitió la cuarta figura en sus sistema porque era incapaz de definirla según los métodos que desarrolló" (p. 114). Ahora bien, estos "métodos" constituyen, según el mismo autor, determinadas claves estándar de formulación que, sin embargo, no tienen ningún peso sustantivo en la argumentación más allá de ser reglas constructivas arbitrarias. "Cualquier formulación estándar de la cuarta figura, como de la primera, debe introducir dos veces el término medio, a causa de su diferente función gramatical en las dos premisas. En este caso, sin embargo, es imposible yuxtaponer sus dos ocurrencias. Y, por lo tanto, Aristóteles no podría dar aquí una definición inequívoca del término medio por medio de su posición en la formulación estándar. Todavía menos podría distinguir el término mayor y menor de esta manera. Podría pensarse, en principio, que el término mayor, que en la primera figura es el primer término de la formulación estándar, podría ser el último término en la cuarta; pero un vistazo a la formulación estándar -si $I$ pertenece a todo $K$ y $L$ pertenece a todo $I . . .-$ mostrará que aquí el término medio ocupa el último lugar (y también el primero). Lo mismo vale para el término menor. Es imposible distinguir los términos mayor y menor por su mayor o menor distancia con respecto al término medio (como se hace en las figuras II y III), ya que 'el' lugar del término medio no puede ser determinado de modo único, y el mayor y el menor están cada uno igual de cercanos y de lejanos a una y otra ocurrencias del medio" (pp. 116-117).
} 


\section{4. - La exigencia sinonímica como fundamento de la primacía

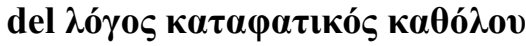

Reparemos ahora, además, en que este supuesto puede retrotraerse a un momento anterior de nuestro análisis: en efecto, la exigencia de determinación sinonímica, que, como hemos visto, se expresa en la condición formal-general de todo ővo $\mu \alpha$ y ṕñ $\mu \alpha$ de "significar algo unitario" y que es la razón del uso de variables (en tanto que éstas recogen sólo tal condición común), es el fundamento de la primacía de la forma A sobre

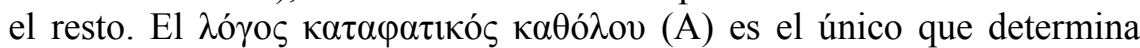
algo de manera positiva e interna a la cosa de la que se trata, esto es, es el único que puede poner de relieve la entidad, la oủoía, de algo. El resto de formas manifiestan aspectos privativos o incidentales. Por lo tanto, es la exigencia de determinación que hemos visto presente en los elementos del $\lambda$ ó os lo que lleva a privilegiar la forma A frente a las demás y, por consiguiente, lo que conduce a que ésta actúe como criterio constructivo de los esquemas de cada figura. La "arbitrariedad" de ese supuesto constructivo es consecuencia de una "arbitrariedad" anterior: el supuesto de que toda presencia está determinada de manera sinonímica, que todo ente posea una entidad ${ }^{39}$.

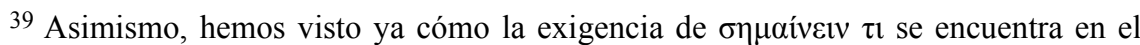
pasaje aristotélico que trata acerca del principio de no-contradicción. La "demostración refutativa" del mismo se basa en dejar que el que lo discute diga algo y, con ello, signifique algo unitario. "El comienzo no es pedir que se diga que algo es o no es (pues esto se consideraría inmediatamente una petición de principio) sino que signifique algo, tanto para él como para otro, lo cual es necesario si es que dice algo, ya que si no [ocurriera esto] no habría $\lambda$ ó ${ }^{\circ} \varsigma$ en aquello, ni para él mismo ni para otro. Y si alguien concediera esto, habrá demostración, pues ya habrá

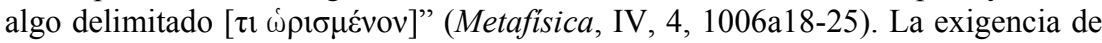
determinación sinonímica es así la otra cara de la imposibilidad que declara el

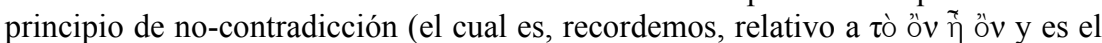
principio más firme de todos). Esta relación con lo expuesto en los análisis precedentes se confirma en el momento en el que se identifica la demostración de este principio con la posibilidad misma del $\lambda$ ó ${ }_{0}$ s: "La causa no será el que demuestra

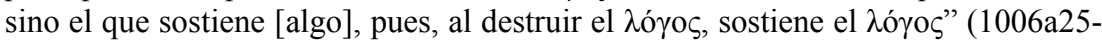
-26). Aquel que discute el principio de no-contradicción trata de destruir el $\lambda$ ó mismo, pero al hacerlo afirma aquello mismo que trata de negar. La exigencia de

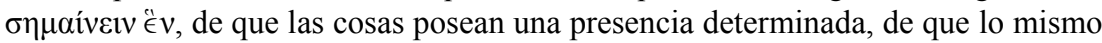
no pueda ser y no ser lo mismo al mismo tiempo y en el mismo sentido, es la condición de posibilidad de todo $\lambda$ ó $\gamma$ os, de todo dialogar y de todo comprender: "Si no lo pusiera [un ővo $\mu \alpha$ distinto a cada $\lambda$ ó $\gamma o \varsigma$ de significado distinto] sino que afirmara que [hombre] significa cosas ilimitadas, es evidente que no habría $\lambda$ ó $\gamma o \varsigma$, pues no significar algo unitario es no significar nada, y al no significar nada los óvó $\mu \alpha \tau \alpha$ se destruye el dialogar recíproco, y en verdad también el dialogar con 
A su vez, ese mismo supuesto fundamenta otra serie de rasgos "arbitrarios" que aparecen en los planteamientos del Órganon. Así, la primacía de la forma A sobre las demás explica el privilegio de la primera figura:

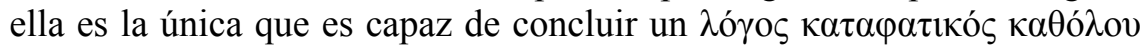
(modo bArbArA). El reconocimiento de esto mismo por parte de Aristóteles se expresa en los siguientes términos (Analíticos Posteriores, I, 14):

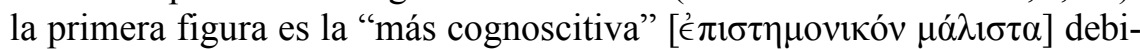

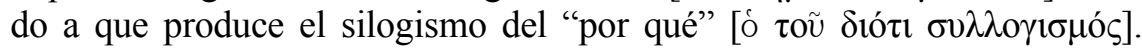
El modo bArbArA es el único que pone de relieve relaciones esenciales entre determinaciones, manifestando la forma misma de una cadena determinativa: si una determinación está incluida en otra y ésta en otra tercera, la primera se halla incluida en la última, o, por decirlo en los mismos términos que antes, una determinación hereda las determinaciones esenciales de sus determinaciones esenciales. El modo bArbArA es la forma silogística privilegiada pues muestra la cadena determinativa poniendo de relieve las determinaciones que se dan ( $\lambda$ ó $о \varsigma \kappa \alpha \tau \alpha \varphi \alpha \tau \iota \kappa o ́ \varsigma)$

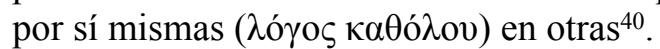

respecto a uno mismo; en efecto, no cabe comprender [

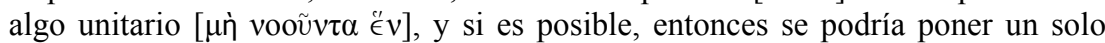
övo $\mu \alpha$ a esa cosa" (1006b5-11). Cfr. B. CASSIN / M. NARCY, La decisión du sens, Paris, J. Vrin, 1989; en especial, p. 33ss.

${ }^{40}$ Muchos autores han insistido en la importancia de la primera figura en este y otros aspectos de la silogística aristotélica, así como han puesto de relieve su carácter "gratuito". Cfr., respecto a la designación de término mayor, menor y medio, W. KNEALE / M. KNEALE, op. cit., p. 66: "La terminología parece haber tenido origen en el hecho de que, en un silogismo del primer modo de la primera figura, el predicado de la conclusión es por lo general el término de mayor extensión". Asimismo, cfr. J. LUKASIEWICZ, op. cit., p. 33: "De hecho, estas explicaciones [del término mayor, menor y medio] pueden ser solamente aplicadas a silogismos del modo Barbara con términos concretos y premisas verdaderas. (...) El modo Barbara, como ley lógica, tiene que ser enunciado con variables. (...) Las explicaciones dadas no son aplicables a esta ley lógica, pues no es posible determinar relaciones extensionales entre variables". Y también G. PATZIG, op. cit., p. 99: "Por supuesto, es fácilmente mostrable que esta definición [la del término mayor, menor y medio] sólo es universalmente aplicable a los términos de un argumento en Barbara con términos concretos y premisas verdaderas". Cfr., a propósito de la reducción (y validación) de las demás figuras en la primera, M. COHEN / E. NAGEL, Introducción a la lógica y al método científico, Buenos Aires, Amorrortu, 1971, p. 109: "Aunque muchos lógicos han considerado el proceso de reducción innecesario y hasta inválido, no hay duda de que, si se admiten los fundamentos sobre los que desarrolla Aristóteles su teoría del silogismo, aquél se convierte en parte esencial de la teoría. Ahora bien, desarrollada la teoría del silogismo sobre otras bases, que no asignen a la primera figura superioridad intrínseca sobre las otras, la reducción no puede tener la importancia que se la ha atribuido tradicionalmente." Asimismo, cfr. M. CORREIA, La lógica de Aristóteles, Santiago, Ediciones Universi- 
Del mismo modo, la presencia de ese supuesto permite explicar otra serie de "peculiaridades" de la lógica aristotélica, como la siguiente declaración:

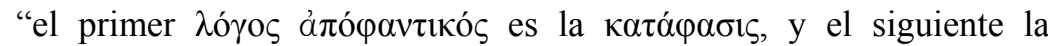

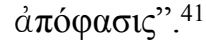

La primacía de la "afirmación" sobre la "negación" corresponde a la

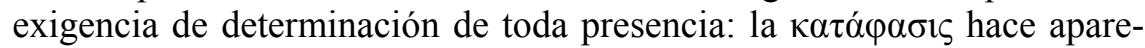
cer los aspectos que pertenecen a la cosa de la que se trata, mientras que

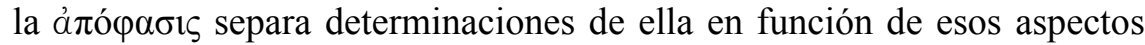
que le pertenecen. Si prescindimos de este supuesto, la declaración aristotélica se nos aparecerá, de nuevo, como una arbitrariedad (explicable, por ejemplo, en función del sistema de signos empleado: primero "...es...", segundo “...no es..." por ser expresión más compleja).

Por lo tanto, situar a la base de nuestra comprensión este presupuesto que parece manejar Aristóteles, por razones que aquí no podemos desarrollar, permite entender las razones de determinadas decisiones que toma el texto de un modo aparentemente arbitrario. Una lectura así permitiría explicar características de la obra lógica aristotélica que de otro modo no pueden menos que pasar por caprichos o incluso errores de la misma.

\section{3. - Conclusión: hacia una lectura diferente}

En los análisis precedentes hemos podido observar que en el uso de variables en la silogística se encuentra operando un cierto supuesto que recorre todo el planteamiento aristotélico (al menos en los textos que hemos manejado), confiriéndole además un carácter específico al mismo (lógico-ontológico). La actitud lógica de la que hablábamos al comienzo del artículo, sin embargo, no puede ver en ello más que una asunción arbitraria que requiere ser corregida. A partir de la interpretación aquí desarrollada, al hacer esto no está cumpliendo, como ella pretende, con el "espíritu" que subyace a la "letra" aristotélica, sino que con ello delata más bien poseer un "espíritu" bien diferente. Desde este tipo de lectura (que aquí hemos explicado sólo de un modo negativo, por la ausencia del supuesto aristotélico), determinadas decisiones relevantes respecto de, por ejemplo, la propia configuración de la silogística sólo pueden enten-

dad Católica de Chile, 2003, p. 103: "Lógicamente considerados, los así llamados imperfectos o incompletos (atelés) cumplen con la definición de silogismo dada por Aristóteles, tal como los llamados, en contraste, perfectos (téleios). Contemplado esto, no se ve ninguna razón intrínseca para que haya reducción."

${ }^{41}$ De Interpretatione, 5, 17 a 9. 
derse como arbitrarias, de suerte que su cancelación (implícitamente presente en la consideración de arbitrariedad) posibilitará nuevos desarrollos (construcción de una cuarta figura, concepción de la silogística como una teoría particular, etc.).

Ahora bien, esta "refundación" de la lógica aristotélica, ¿puede seguir declarándose heredera suya o más bien habría que ver en ella una reelaboración y reinserción en una perspectiva distinta de materiales que pertenecen a otra configuración estructuralmente heterogénea? Para responder de manera adecuada a esta pregunta sería preciso determinar de manera positiva las relaciones entre la investigación aristotélica y la actitud lógica que hemos venido diferenciando de ella.

Sin perjuicio, repetimos, del innegable rendimiento histórico del "espíritu lógico", el presente artículo espera haber planteado, al menos, algunas dudas acerca de su rendimiento hermenéutico con respecto a la obra lógica aristotélica y haber esbozado la posibilidad de una interpretación diferente que no requiera tanta "purificación textual". Una lectura tal podría desmarcarse de los esquemas clásicos y relacionar de un modo hermenéuticamente más fecundo al Organon con sus predecesores griegos. En efecto, como mero apunte, baste señalar, para concluir, que ese supuesto que hemos visto comparecer en los análisis aristotélicos podría relacionarse con otras formulaciones relativas a la entidad general de las cosas que son propias del mundo griego. El que cada cosa posea una entidad, el que esté internamente determinada de manera sinonímica, podría entenderse, en efecto, como la peculiar versión aristotélica de la concepción griega de la finitud irreductible de lo ente o, por decirlo con la clásica sentencia de Tales, de que todo está lleno de dioses.

\section{RESUMEN}

Una lectura lógica del Organon aristotélico descubre ciertas incoherencias en el texto que debe resolver reduciéndolas a decisiones metafisicas del autor cuando no señalándolas como deficiencias en la exposición que es preciso corregir. El presente artículo trata de desplegar una línea de lectura que atienda más bien a esas "incoherencias", tratando de entenderlas como pasos específicos de la investigación aristotélica. Para ello se centra en el procedimiento de exposición de las figuras aristotélicas, el uso de variables, cuya "invención" por parte de Aristóteles ha sido encomiada a lo largo de la tradición lógica. Un análisis de los rasgos propios e internos de este procedimiento permitirá enlazar la investigación aristotélica del lógos con la investigación de "el ser en cuanto ser", así como determinar, si bien de modo negativo, la relación entre esta lectura y la lógico-tradicional del Organon.

Palabras clave: Organon, variables, lógica aristotélica, lógos. 


\begin{abstract}
A logical reading on Aristotle's Organon discovers some inconsistencies in the text which have to be solved by reducing them to metaphysical decisions of the author, if they are not just identified as deficiencies in the exposition that should be corrected. The present article tries to display a line of reading paying attention to those so-called inconsistencies, in an attempt to understand them as specific steps in Aristotle's research. In order to this goal it focuses on the exposition procedure of the Aristotelian figures: the use of variables, whose introduction by Aristotle has been celebrated all over logical tradition. An analysis of the distinctive and internal features in this procedure will allow us to link Aristotle's logos research and the "being qua being" investigation, and to determine also -though in a negative way- the connection between this reading and the logical-traditional one on Aristotle's Organon.
\end{abstract}

Keywords: Organon, variables, Aristotelian logic, logos. 